\title{
Behcet's Disease Presenting as Fever of Unknown Origin : A Case Report
}

\author{
SAMADT ${ }^{\mathrm{a}}$, AHMED JU ${ }^{\mathrm{b}}$, RAHIM MA ${ }^{\mathrm{b}}$, MUSAAKM ${ }^{\mathrm{c}}$, UDDIN KN ${ }^{\mathrm{d}}$, HOSSAIN MD $^{\mathrm{c}}$, \\ AHMED AKMS ${ }^{e}$, HAQUE HF $^{\mathrm{f}}$
}

\begin{abstract}
Behcet's disease (BD) is an inflammatory disease characterized by recurrent oral aphthous ulcers and numerous systemic manifestations. The underlying cause of Behcet's disease is unknown. As with other autoimmune diseases, the disorder may represent aberrant immune activity triggered by exposure to an antigen, perhaps infectious, in patient with a genetic predisposition to develop the disease. Here we are reporting a case of Behcet's disease in a 50 year
\end{abstract}

\section{Introduction}

Behcet's syndrome is an inflammatory disorder of unknown etiology that involves arteries and veins of all size. The first description of Behçet's disease was probably by Hippocrates in the fifth century $\mathrm{BC}^{1}$, and the first modern account was presented in 1937 by the Turkish dermatologist Hulusi Behçet, who reported on a patient with recurrent oral and genital aphthae and uveitis.

a. Dr. Tabassum Samad, FCPS (Medicine), Registrar, Nephrology, Ibrahim Medical College and BIRDEM General Hospital, Shahbag, Dhaka 1000, Bangladesh.

b. Dr. Jamal Uddin Ahmed, FCPS (Medicine), Dr. Muhammad Abdur Rahim, FCPS (Medicine), Registrar, Internal Medicine, Ibrahim Medical College and BIRDEM General Hospital, Shahbag, Dhaka 1000, Bangladesh.

c. Dr. AKM Musa, FCPS (Medicine), Dr. Md. Delwar Hossain, MD (Chest), Associate Professor, Internal Medicine, Ibrahim Medical College and BIRDEM General Hospital, Shahbag, Dhaka 1000, Bangladesh.

d. Prof. Khwaja Nazim Uddin, FCPS (Medicine), FRCP, Professor and Head, Internal Medicine, Ibrahim Medical College and BIRDEM General Hospital, Shahbag, Dhaka 1000, Bangladesh.

e. Dr. AKM Shaheen Ahmed, FCPS (Medicine), Assistant Professor, Internal Medicine, Ibrahim Medical College and BIRDEM General Hospital, Shahbag, Dhaka 1000, Bangladesh.

f. Dr. Hasna Fahmima Haque, FCPS (Medicine), Registrar, Haemodialysis Ibrahim Medical College and BIRDEM General Hospital, Shahbag, Dhaka 1000, Bangladesh.

Address of Correspondence: Dr. Tabassum Samad, FCPS (Medicine), Registrar, Nephrology, Ibrahim Medical College and BIRDEM General Hospital, Shahbag, Dhaka 1000, Bangladesh. E-mail: samadtabassum@yahoo.com.

Received: 30 November 2011 Accepted: 12 October 2012 old gentleman who presented with fever, recurrent oral ulcers and genital ulcer. Diagnostic workup excluded other possible diseases. Pathergy test was positive. Prednisolone was started along with other supportive therapy and patient subsequently improved.

Key Words: Behcet's disease, Inflammatory disease, Pathergy test

(Birdem Med J 2013; 3(1):50-53)

It commonly occurs between 20s and 30s, but no age is exempted and both sexes are equally affected. Susceptibility to Behçet's disease is strongly associated with the presence of the HLA-B51 allele. ${ }^{2,3}$ Environmental factors such as infectious agents have also been implicated in its pathogenesis. ${ }^{4}$ Cases of Behcet's disease (BD) cluster along the ancient silk road which extends from eastern Asia to the Mediterranean basin. $^{5}$

Clinical features of Behcet's disease include recurrent oral ulcers (97-99\%), genital ulcers (85\%), ocular (50\%) and cutaneous lesion (85\%), arthritis (50\%) and vascular disease (30\%). All these common manifestations are selflimiting except for the ocular attacks. Repeated attacks of uveitis can cause blindness. Other complications include major vessel thrombosis and CNS involvement. ${ }^{6,7}$

There is no definite diagnostic test for $\mathrm{BD}$ and diagnosis depends on various diagnostic criteria. According to the International Study Group (ISG) criteria, ${ }^{8} \mathrm{BD}$ is diagnosed with recurrent oral ulcer and any 2 of the following: recurrent genital ulcer, eye lesion (anterior and posterior uveitis), cells in vitreous, retinal vasculities and positive pathergy test. According to O’Duffy (OD) criteria a patient is diagnosed as BD if (S)he has recurrent apthous ulcer with any 2 of following: genital ulcer, uveitis, cutaneous pustular vasculities, synovitis, meningoencephalitis with the exclusion of inflammatory bowel disease (IBD), systemic lupus erythematosus (SLE), Reiter's syndrome and herpetic infection. 
Little is known about its incidence or prevalence in Bangladeshi people. Because of under reporting of this disease, BD often does not come as a differential diagnosis in our physician's mind. Milder cases are readily missed. Here we report a case of 50-year-old man, who presented with fever and mucocutaneus ulceration for 3 months. He was diagnosed as a case of Behcet's syndrome according to International Study Group Criteria for BD.

\section{Case Report}

A 50-year-old gentle man presented with 3 months history of low grade, intermittent fever along with evening rise of temperature. There was no other focal symptom. He had repeated episodes of oral ulcers during that time. Few days prior to hospitalization, he noticed painless ulcers over his scrotum and penis. He did not

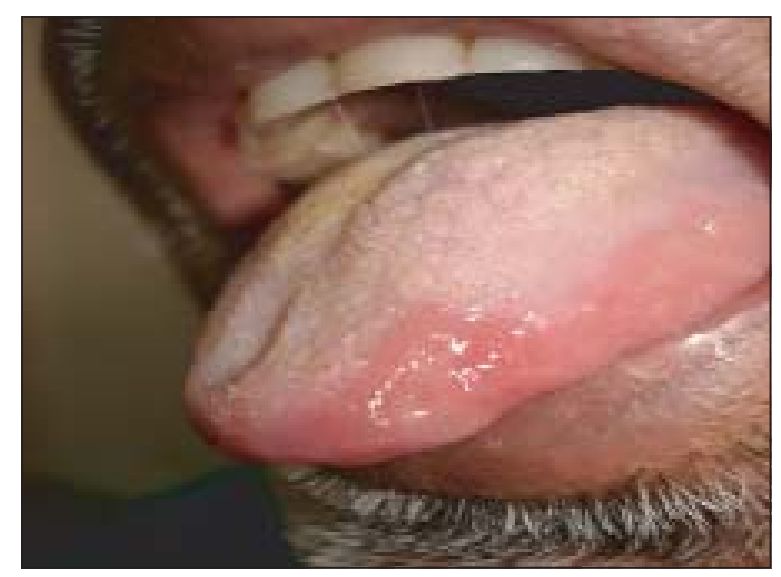

Fig.-1: Ulcers on tongue

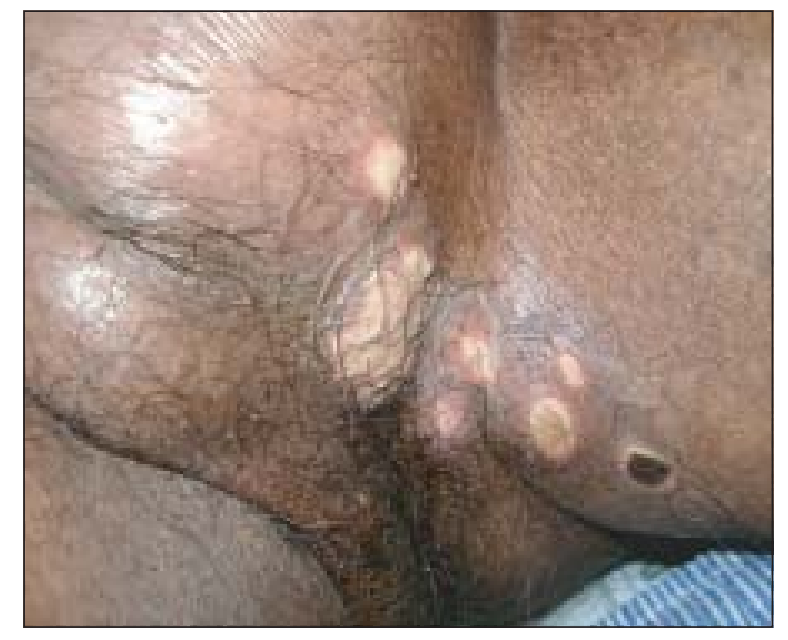

Fig.-2: Multiple ulcers over penis and scrotum have any history of unprotected, extramarital sexual exposure. His bowel habit was normal. On admission he had fever of $101^{0} \mathrm{~F}$. He had multiple ulcers on dorsal and lateral surface of tongue (Fig.-1) and on the shaft of penis and scrotum (Fig --2). Ulcers were circular with sharp margin, base was moist and slough was present. There was no lymphadenopathy, organomegaly or ocular involvement. Other systemic examinations were normal.

Laboratory investigation revealed anemia, leukocytosis, high ESR and high C-reactive protein (CRP). Peripheral blood film (PBF) was non-specific. Blood and urine culture revealed no growth. Febrile antigen was not significant. Imaging of chest and abdomen showed no significant changes. Mantoux test, VDRL and TPHA were negative. Liver and renal function tests, urine analysis, ANA and markers for hepatitis B and C yielded normal result. Anti HSV IgG was positive but IgM was negative. Pathergy test was performed using an intradermal 21-gauge needle puncture on the skin of the forearm. Small papule was formed over skin within 48 hours (Fig.-3). Finally we diagnosed him as having BD according to the diagnostic criteria of International Study group (ISG) for BD. Treatment with oral prednisolone was started at the dose of $1 \mathrm{mg} / \mathrm{kg} / \mathrm{day}$. Patient became afebrile from $4^{\text {th }}$ day of starting prednisolone with improvement of general condition. He was discharged with advice for follow-up after 4 weeks. On follow-up the patient was afebrile and the ulcers healed without any further relapse.

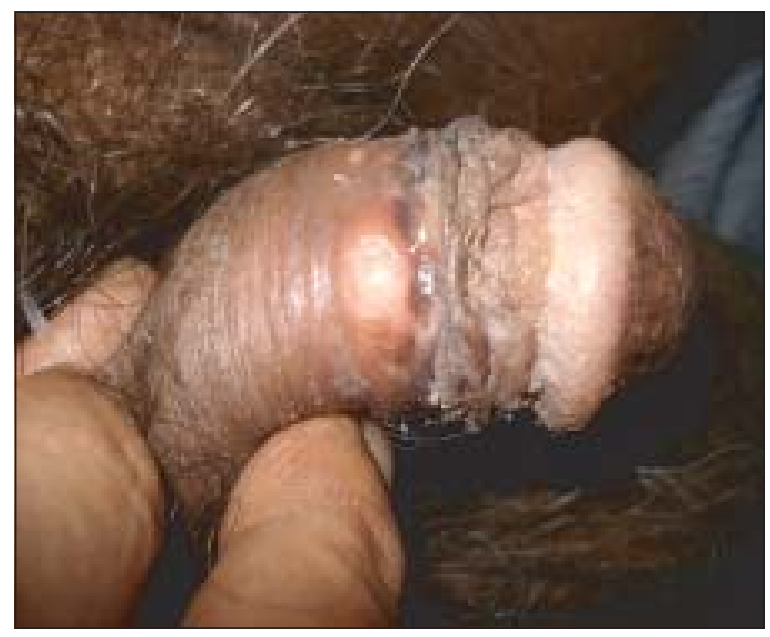



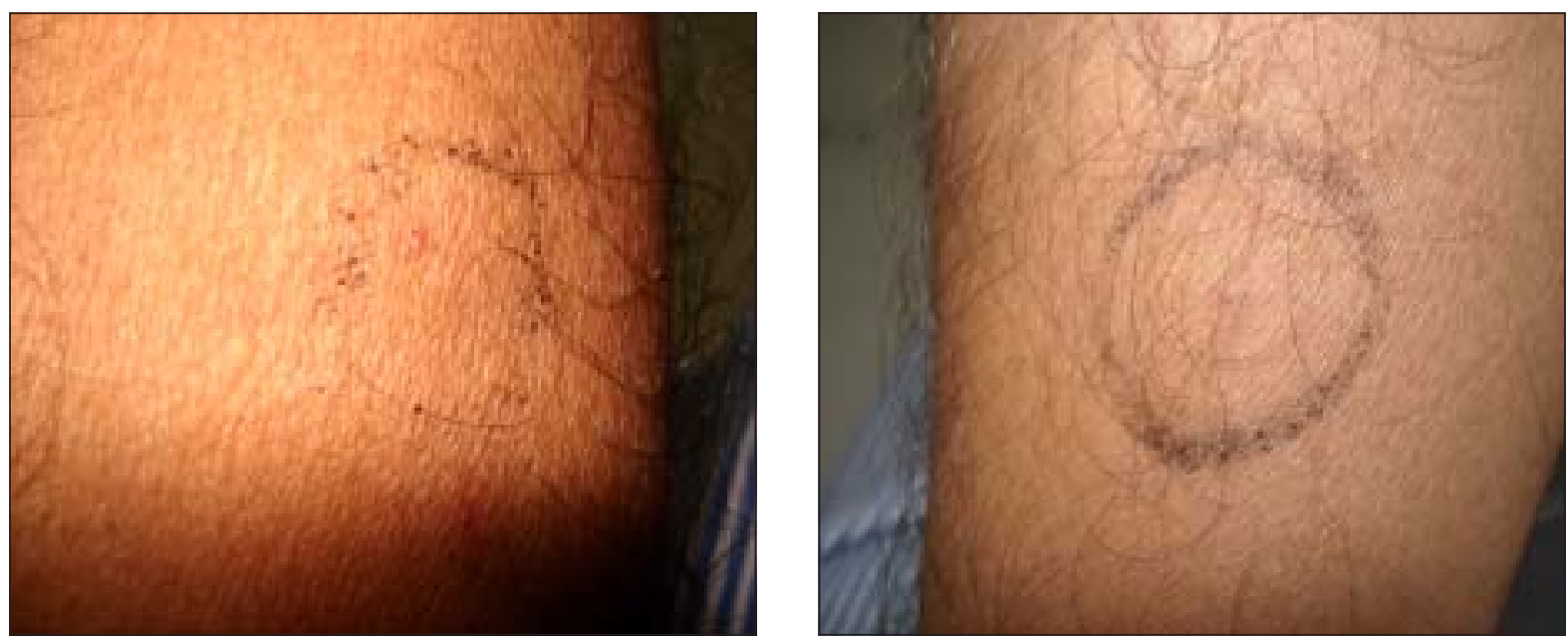

Fig.-3: Pathergy test

\section{Discussion}

The diagnosis of Behçet's disease is often difficult to establish because of the absence of pathognomonic symptoms, signs, or laboratory findings at the onset. Our patient initially presented with fever and recurrent oral ulcers, then he developed genital ulcer. History, examination findings and investigation excluded IBD, SLE or any other infectious disease. In a series of 37 patient in a tertiary rheumatology clinic in Singapore, 23 (62.2\%) satisfied both ISG and OD criteria, 14 (37.8\%) did not fulfill the ISG criteria but fulfilled the OD criteria and of these 6 were the incomplete form and 8 complete form. ${ }^{9}$ Our case had recurrent oral ulcers and genital ulcer with positive pathegy test, thus met the International Criteria and also fulfilled OD criteria incompletely.

The same study showed commonest presentation of BD was recurrent oral ulcer (100\%), genital ulcer (64.9\%), joint (56.8\%) and cutaneous manifestation (48.6\%). Commonest systemic manifestation were arthritis (43.2\%), GI manifestation ( 40.5\%) and uveitis (35.1\%). ${ }^{9}$ Few study and case report have showed protracted fever of unknown origin as the presenting symptom of BD. ${ }^{10-}$

13 Fever may accompany other acute manifestation during the course of the disease. ${ }^{12}$ Because BD lacks any pathognomonic symptom and laboratory findings, the diagnosis relies largely upon the diagnostic criteria. ${ }^{14}$

Treatment response in BD is unpredictable and the choice of the treatment depends on the patient's clinical manifestations. Priority is given to the treatment of gastrointestinal symptoms, central nervous system involvement, and large-vessel lesions, which require high-dose corticosteroids, immunosuppressants, or both and, in some cases, surgical intervention. Very little is mentioned about the treatment of fever in BD. Many drugs have been tried in the treatment including antibiotics, anti-inflammatory, corticosteroid and others; all with equivocal effect. ${ }^{11}$ In this case we treated our patient with oral corticosteroid and the patient improved significantly.

\section{Conclusion}

In spite of recent advances in treatment, the functional prognosis of patients with Behçet's disease remains unsatisfactory. The final goal is to elucidate the pathogenesis of the disease and develop treatments aimed at the underlying pathologic process. Although not frequently encountered still this disease should be considered as a differential diagnosis of fever of unknown origin. Further studies for elucidation of the etiology, improvement of the diagnostic criteria and development of new therapy are needed to conquer the disease.

\section{References}

1. Feigenbaum A. Description of Behçet's syndrome in the Hippocratic third book of endemic diseases. $\mathrm{Br} \mathrm{J}$ Ophthalmol 1956; 40: 355.

2. Mizuki N, Inoko $\mathrm{H}$, Ohno S. Pathogenic gene responsible for the predisposition to Behçet's disease. Int Rev Immunol 1997; 14:33-48 
3. Ohno S, Ohguchi M, Hirose S, Matsuda H, Wakisaka A, Aizawa M. Close association of HLA-B51 with Behçet's disease. Arch Ophthalmol 1982; 100: 1455-58.

4. Lehner T. The role of heat shock protein, microbial and autoimmune agents in the aetiology of Behçet's disease. Int Rev Immunol 1997; 14:21-32

5. Kaikamani VG, Vaiopoulos G, Kalkamani PG. Behcets disease. Semin Arthritis Rheum 1998; 27: 197-217.

6. Kastner DL. Intermittent and periodic arthritic syndromes. In: Koopman WJ, ed. Arthritis and allied conditions: a textbook of rheumatology. 13th ed. Vol. 1. Baltimore: Williams \& Wilkins, 1997:1279-1306.

7. Yazici H. Behcets syndrome: where do we stand? Am J Med 2002; 112: 75-76.

8. International Study Group for Behcet's Disease. Criteria for diagnosis of Behçet's disease. Lancet 1990; 335: 1078-80.
9. Cheng YK, Thong BY, Chng HH. Behcet's disease: experience in a tertiary Rheumatology Centre in Singapore and a review of the literature. Ann Acad Med Singapore 2004; 33(4): 510-14.

10. Baky A, Mansour HE, Ibrahim SL. Prevalence of connective tissue disease in Egyptian patient presenting with fever of unknown origin. Clin Med Insights 2011; 4:33-41.

11. Fatima J, Shukla V, Karoli R. Behcet's syndrome presenting as FUO. J Assoc Physicians India 2010; 58: 331-32

12. Niamane R, Moudden MK, Zyami M. Protacted fever of unknown origin as the presenting symptom of Behcets disease. Joint Bone Spine 2005; 72(2): 175-76.

13. Salin I, Kursad O, Koray U, Sukru S. Prolonged fever: an atypical presentation of Behcet's disease. Rheumatology International 2011; 6: 839-40.

14. Kurakawa MS, Suzuki N. Behcet's disease. Clin Exp Med 2004; 4(1):10-20. 